\title{
COVID-19: The Disproportionate Impact on Underserved K-12 Students
}

Author 1, ORCID: https://orcid.org/0000-0002-1622-9796

Author 1 Affiliation: Janelle C. Hall, PhD, Walden University, Minneapolis, MN

Author 2, ORCID: https://orcid.org/0000-0002-5530-5675

Author 2 Affiliation: Leonard. B. Jackson, EdD, University of Phoenix, Phoenix, AZ

Author 3, ORCID: https://orcid.org/0000-0001-6140-236x

Author 3 Affiliation: Taurus J. Jackson, DM/IST, University of Phoenix, Phoenix, AZ

SC Classification Genre: Education

Creative Commons Attribution (c) (i) ()

Citation: Hall., J. C., Jackson L. B., \& Jackson, T. J. (2021). COVID-19: The disproportionate impact on underserved K-12 students. Scholar Chatter, 2(2), 12-21, http://doi.org/10.47036/SC.2.2.12-21.2021

(C) The Authors. 2021. This is an open access publication through Scholar Chatter LLC.

\begin{abstract}
The purpose of this content analysis was to show the impact COVID-19 had on K-12 instructional method delivery, technology, learning, and academic achievement. The following questions guided the content analysis: How did COVID-19 impact student and academic achievement, how did the pandemic impact education and instruction method delivery in a virtual learning environment, and how did the pandemic affect teacher \& student access to technology? The population consisted of K-12 educational leaders and students who completed surveys in previous studies. The findings via content analysis revealed that online education seems to be deeply rooted in the careful planning of instruction. We found that leaders were having a difficult time making the necessary adjustments with remote learning. Thus, the impact of COVID-19 has changed the way many students come to class. There is a need for K-12 institutions to strengthen their best practices relating to online curriculum and instruction demonstrated during in-person learning.
\end{abstract}

Key Words: Student learning K-12, academic \& instructional effectiveness, technology effectiveness, COVID-19, underserved communities

\section{Introduction}

COVID-19 has shifted the way we view normalcy and introduced uncertainty in educational and instructional methodologies, student learning environments, and access to technology. Additionally, COVID-19 has placed several constraints on parents while limiting educational opportunities for students. With the absence of data on student learning and 
instructional effectiveness and student learning and technology effectiveness, the decision to return to in-person learning remains extremely difficult. In addition to the uncertainty of COVID-19, mental health with students in secondary education is also a major concern. Exiting research demonstrates how academic achievement and mental health are linked and can lead to emotional problems among students if left untreated.

The consequences of the pandemic will have an indelible impact on the student's mental health due to the combination of the pandemic crisis, social isolation, and academic gap. The impact on mental health has magnified with COVID-19 and economic burdens on Black and Hispanic families facing these unprecedented times. Therefore, we must examine the short- and long-term effects on academics and mental health based on the impact of COVID-19. The pandemic's impact is ongoing and requires continuous examination of students' $\mathrm{K}-12$ academic progress and reliable technology in underserved communities to establish coordinated efforts to communicate academic gains and losses and widen the academic achievement gap. The recommendations of this study were designed to help support student achievement and strengthen mental health.

\section{Literature Review}

\section{COVID-19 and Student Academic Achievement Gap}

New evidence shows that the shutdown caused by the pandemic potentially exacerbated achievement gaps. It has become clearer that the education system is susceptible to external dangers (Bozkurt \& Sharma, 2020). The United States of America's educational system was not prepared to deal with the effects imposed by the COVID-19 pandemic. Parents and schools tried to keep the learning processes going. However, through those efforts, the likelihood to provide the expected high level of rigor of education to be delivered in the classroom rapidly diminished (Han \& Ellis, 2019). Research conducted by the American Enterprise Institute found that only one in five school districts met their standard for rigorous remote learning (Malkus, 2020). Nationally, teachers estimated that their students spent half as much time learning as they did before the COVID-19 school closures (Slavin \& Storey, 2020). COVID-19 caused disproportionate learning losses between White, Black, and Hispanic students to existing gaps. The average Black or Hispanic student remains roughly two years behind the average White student, and low-income students continue to be underrepresented among top performers (Hanushek et al., 2020). Some students are getting poor quality remote learning.

Inequality of students is a result of the socio-economic status factor. Students from lowincome households will find difficulty adapting to remote learning due to school closures (Ribeiro, 2020)). The greatest learning loss will be among low-income Black and Hispanic students. Al-Kilidar and Sixsmith's (2021) research findings revealed that students with no internet access during this COVID-19 pandemic would continue to struggle with academic achievement. Additionally, the rate of internet access declined rapidly. By implication, students with no or low socio-economic power to afford broadband connection are most vulnerable to fall behind or encounter additional challenges to meet up with others in online learning. Low-income 
households will less likely have access to a sustainable learning environment to support highquality remote learning (Quezada et al., 2020).

K-12 students encounter challenges leading to poor mental health in the wake of the pandemic. Before the pandemic, one in five K-12 students experienced one or more diagnosable mental disorders worldwide (Hanushek et al., 2020). The fact that the COVID-19 pandemic affects secondary education student's mental health underscores the need to understand these challenges and concerns to inform the development of courses of action and messaging that can better support K-12 students in this crisis.

Nearly early two-thirds of parents say their child has experienced mental challenges such as anxiety, depression, and even suicidal thoughts, according to a national survey on student well-being during the pandemic (Prime et al., 2020). Though the growing concern of the pandemic and its widespread disruptions to educational institutions placed a devastating, longlasting toll on students' mental health, the Jed Foundation survey offers some optimism. The survey offers imperative insight into the challenges students have experienced over the pandemic, most importantly highlighted resilience among young people.

\section{COVID-19 and Education Instruction Method Delivery}

The impact of COVID-19 on education and instructional method delivery has been challenging in many school settings. These school settings are not limited to elementary schools, middle schools, or high schools. The online learning platform is not an innovative idea. Online learning platforms have been around since the 1980s, 1990s, and 2000s (Ribeiro, 2020). Online delivery was viewed as an optional alternative way working adults attend school. Online delivery had not been taken seriously as a learning format or instructional option.

Furthermore, this instructional delivery model was not considered a serious model that guaranteed effective quality instructional activities (Ribeiro, 2020). However, due to the COVID-19 pandemic, school districts have had to use forward-thinking to restructure instructional delivery (Ribeiro, 2020). With the acceptance of social distancing guidelines, as established by the World Health Organization (WHO), instructional deliveries have been online. In turn, this forced many school districts to close doors and disrupt the traditional ways in which teachers delivered instruction to the students (Strielkowski, 2020).

School districts serving students in the K-12 setting have shifted their attitudes in response to the global closures of school districts (Vlachopoulos, 2020). As a result of global school closures, instructional deliveries such as online learning have been implemented to measure student achievement. Online instructional deliveries have also been a measure to maintain social distance measures (Vlachopoulos, 2020). These measures have decreased COVID-19 contact among faculty, students, and personnel in the school systems (Vlachopoulos, 2020). In addition, schools have been fortunate to switch the methods in which they deliver instruction. Schools have used multiple delivery methods to deliver instructional activities, including face-to-face, online, and hybrid learning models (Strielkowski, 2020; Vlachopoulos, 2020). 
Many school districts successfully ran distance learning education platforms prior to the pandemic (Ribeiro, 2020; Strielkowski, 2020). With the widespread school closures due to CDC COVID-19 guidelines, there was only one option: distance education (Ribeiro, 2020). K-12 and other institutions of higher learning were able to engage in some level of digital transformation processes to engage students and meet learning objectives (Ribeiro, 2020; Strielkowski, 2020). Elementary schools, middle schools, and high schools worldwide have created online instructional delivery methods using technology assisting platforms to meet the learning needs of their student population amidst the COVID-19 crisis (Ribeiro, 2020).

\section{COVID-19 and Technology Access}

Although K-12 institutions have been exposed to various technology and applications to facilitate instruction, the increase in usage highlighted the disparities in accessing technology and applications in the workplace and at home (Quezada et al., 2020). Therefore, it is up to the leadership of these K-12 institutions to act promptly and develop a comprehensive technology plan. The comprehensive technology plan should address the technology and applications currently available, teacher and student accessibility, and technology effectiveness (Yang, 2020). Inadequate access to technology, applications, and dependable internet connection is one of the greatest challenges recognized among teachers and students (Trinidad, 2021). The COVID-19 pandemic presented teachers and students with unique technology access issues.

While many K-12 institutions have been exposed to various technology and applications, the ability to properly implement and measure technology effectiveness has been vulnerable during the COVID-19 pandemic; the lack of access to technology can be seen mainly in underserved communities (Trinidad, 2021). However, since implementing additional technology and applications, students have increasingly struggled in the virtual environment by not submitting assignments and being held liable (Kavrayıcı \& Kesim, 2021). Although facilitating instruction through technology is significant for many K-12 institutions, they will need to confirm that teachers and students can access and understand how to use the technology and applications (Sá \& Serpa, 2020). Consequently, it will be imperative for both teachers and students to learn how to participate effectively in the virtual environment and other hybrid learning models (Darling-Hammond \& Hyler, 2020). Before the COVID-19 pandemic, many teachers were having difficulty reaching several students due to issues beyond their control (Wilmer et al., 2017).

As a result of the COVID-19 pandemic, K-12 institutions had to implement new technology and applications to foster a creative environment. Applications used to foster such an environment included but were not limited to Learning Management Systems (LMS) such as Google Classroom, Blackboard Learn, and Moodle. Cloud storage applications such as Google Drive and Dropbox were also used to store teacher and student information. Content collaboration applications such as Zoom, Cisco WebEx, and Microsoft Teams were also used to enhance the learning environment. For technology to be effective during the COVID-19 and beyond, K-12 institutions must be prepared to implement monitoring strategies. Strategies include but are not limited to gauging teacher and student access to the internet and applications and access to current and future technology tools for online learning (Wilmer et al., 2017). These 
types of monitoring strategies are vital to comprehending how teachers and students can facilitate routine instruction.

\section{COVID-19 and Learning Achievement}

If the United States acts expeditiously and effectively, it may intervene in the worsening of existing inequities. The absence of the cautious design and development process (Walling, 2016) in the migration process gave birth to the rejection of the contemporary online education experience during this pandemic as effective online education but rather as emergency remote teaching (Bozkurt \& Sharma, 2020; Hodges et al., 2020; Vlachopoulos, 2020). It is critical to support vulnerable students. Educational institutions must think creatively and support summer school learning.

Effective online education consists of online teaching and learning, the boosting of several research works, principles, prototypes, theories, ethics, and appraisal of benchmark concentrations on quality online course design, teaching, and learning (Bozkurt \& Sharma, 2020; Hodges et al., 2020). Educators must learn to make curriculum more effective whatever the scenario. Teachers need to be provided with the necessary resources to show them how to provide virtual engagement, effective instruction, and train them on best practices for remote learning.

The effect of virtual instruction is challenging, even given this body of research evidence, because the conditions within prior research are different from the COVID-19 school closure situation. Extant studies compared the outcomes of students who received similar online versus traditional face-to-face instruction time (The Jed Foundation, 2021). However, students who did not receive online instruction may have had no instruction at all. In addition, while certain factors might improve COVID-19 remote instruction, others make it even harder to achieve effective online instruction, including teachers' lack of training on remote instruction.

Furthermore, the role of academic institutions in providing mental health opportunities for students in secondary education had a severe economic downturn created by the pandemic, recent police shootings of African Americans, and civic unrest likely have created additional turmoil and trauma for children of color. In response to the killing of George Floyd in Minneapolis and others, protests and demonstrations persisted throughout the country. Prior research shows that such events negatively affect student achievement in schools (The Jed Foundation, 2021).

\section{Methodology}

The purpose of this content analysis was to show the impact COVID-19 had on K-12 education, instruction method delivery, technology, learning, and academic achievement. Each author of this research collected three to five articles relating to COVID-19 and how K-12 institutions responded to the shift from face-to-face instruction to remote learning. We performed a deep dive into how COVID-19 is affecting schools via content analysis. The impact of COVID-19 has changed the way many students come to class. Education and instructional methods have presented challenges to many school districts. 
The content analysis review discussed the impact COVID-19 had on student learning and achievement instead of focusing on a specific sociological perspective. Although there are sociological perspectives such as social change, critical, and social interaction theories, we wanted to show the impact COVID-19 had on the academic learning environments. Student achievement gaps are still a critical area this pandemic has impacted. Consequently, this pandemic will continue to be ever-changing and related to instructional method delivery, technology, learning, academic achievement, and underserved K-12 students.

\section{Population and Sample}

The population consisted of K-12 educational leaders and students who completed surveys in previous studies. We located a wide variety of survey research based on the following criteria: K-12 institutions, online learning, and technology types. The criteria review allowed us to examine the available content via online resources (Sheffer \& Hunker, 2019). The samples selected for this content analysis included examining a multitude of COVID-19 related content. Additionally, the method allowed the research to appeal to a variety of demographics.

\section{Data Collection}

We analyzed various ways that COVID-19 affected schools via survey comparisons and content analysis to develop cohesive themes and patterns. We were able to find relative information upon taking a closer look at present content and research available concerning the importance of K-12 academic achievement, instruction delivery, technology, and mental health issues.

\section{Findings}

The findings via content analysis revealed that online education is deeply rooted in the careful planning of instruction. The following questions guided this research:

RQ1: How did COVID-19 impact student and academic achievement?

RQ2: How did the pandemic impact education instruction method delivery in a virtual learning environment?

RQ3: How did the pandemic affect teacher and student access to technology?

The COVID-19 crisis caused school districts and even universities to consider online education post-pandemic. Having schools investigate a crisis-response method of delivery of instruction benefited secondary and post-secondary institutions across the United States. Thus, effective instruction via the online learning model was effective. Online instruction has become a necessary platform and medium for academic achievement, remote teaching, and instruction. We wanted to show the impact COVID-19 had on education, instruction method delivery, technology, learning, and academic achievement by conducting this research. Part of our research required an in-depth investigation into how COVID-19 affected schools via a literature review content analysis. 
Han and Ellis (2019) mention faculty assistance for students as being able to recognize the importance of learning in various modes, including blended learning, discussions, and integrating online discussions as well as face-to-face learning that is still occurring in the traditional settings. More importantly, the implementation of solutions to technical situations was tested to ensure remote learning could be implemented properly. We found that despite the sudden change in how instructional delivery shifted from in-person class to online learning platforms during the pandemic, students, educational leaders, and health leaders could explore untapped opportunities. It is critical and evident that online learning platforms will be educational and sustained to become more hybrid in the future.

We found that leaders were having a difficult time making the necessary adjustments with remote learning. Thus, the impact of COVID-19 changed the way many students come to class. Education and instructional method delivery have presented challenges to many school districts as well as how these districts are using technology. COVID-19 has impacted how students learn, achievement levels, and mental health issues among learners.

\section{Discussion}

The pandemic was successful, forcing a global shutdown of educational activities, which resulted in a digital revolution serving as the new educational platform. Due to the global crisis introduced by COVID-19, innovations in education that would take years due to bureaucracy are now implemented promptly. COVID-19 has revealed emerging vulnerabilities in education worldwide. Evidence has shown that education platforms need to be flexible and resilient in the face of emergencies. Based on our observations, pandemic guidelines, experiences, and recent studies, our findings revealed that resources, confidence, student accessibility, educator readiness, and motivation are integral to online learning. There is a great need for education systems to improve so that teachers can strengthen their practices, update curriculum, and become more responsive to the learning needs of students beyond the traditional classroom. This article introduces how K-12 students are affected and how educational leaders can respond to future challenges.

\section{Recommendations}

The first recommendation we suggest is that secondary and post-secondary educational institutions document and share lessons learned about the impact COVID- 19 had on their educational efforts. Through this content analysis, there is a need for K-12 schools to strengthen their best practices with online curriculum and instruction that continues to demonstrate the rigor demonstrated during in-person learning. Schools should become more responsive to the disparity of the learning needs of students of color. Policy and decision-makers worldwide may benefit from these findings while formulating policy recommendations and strategies to support the current and future pandemics. Findings recommend that online learning is paramount during quarantine due to pandemics. This research provides a strong platform for further research.

The second recommendation is that after a mode for instructional delivery is established, educational leaders should find a more innovative method to implement assessments in the online platforms. These assessments are meant to measure the effectiveness of the online 
environment, including but not limited to objective tests, quizzes, and exams (Malik \& Rana, 2020). Tests and assessments must measure the effectiveness of teacher planning, development, relevancy, and accuracy of the exam items written by the instructors. However, in the online learning environment, assessments should be proxied to eliminate erroneous student behavior (Malik \& Rana, 2020).

The final recommendation is test formatting during the COVID-19 crisis. It is imperative that testing continue to occur despite the pandemic. Learners should be assessed over the material covered, even in an online setting. There are several ways in which teachers and school leaders can assess their learners. Additionally, there are alternate testing formats that can be conducive to the online learning formats. Testing is a way to ensure students process information and maintain the standards. Testing formats include but are not limited to performance-based testing, sentence-completion (fill in the blank) format, short answer format, true-false, and matching format. Furthermore, we recommend making modifications to the grading systems due to the pandemic that, at the time of this research, caused students to become mentally depressed from making the necessary adjustments during one of the most difficult times in their learning experiences.

\section{Conclusion}

COVID-19 has caused school leaders, technology specialists, and mental health leaders to shift how they are reaching their respective populations. There have been uncertainties, including educational and instructional methodologies, online learning environments, and accessing improved technology. Despite these changes, COVID-19 allowed educators who may or may not have been accustomed to the online environment the opportunity to shift their ways of thinking. Changes in the delivery of education have vastly molded how we can impact schools and learning, even amid a pandemic.

\section{Funding}

The authors received no financial support for the research, authorship, and/or publication of this article.

\section{Acknowledgments}

We would like to thank Dr. Julie Conzelmann for her support and guidance during this process. We would also love to show our gratitude to Scholar Chatter, LLC for providing a space for us to continue our scholarly research endeavors.

\section{References}

Al-Kilidar, H., \& Sixsmith, A. (2021). Transition to online learning during COVID-19: What do students think? Journal of e-Learning and Higher Education, 1-13. https://doi.org/10.5171/2021.919218

Bozkurt, A., \& Sharma, R. C. (2020). Emergency remote teaching in a time of global crisis due to coronavirus pandemic. Asian Journal of Distance Education, 15(1), i-iv. 
Darling-Hammond, L., \& Hyler, M. E. (2020). Preparing educators for the time of COVID and beyond. European Journal of Teacher Education, 43(4), 457-465. https://doi.org/10.1080/02619768.2020.1816961

Han, F., \& Ellis, R. A. (2019). Identifying consistent patterns of quality learning discussions in blended learning. The Internet and Higher Education, 40, 12-19. https://doi.org/10.1016/j.iheduc.2018.09.002

Hanushek, E. A., Peterson, P. E., Talpey, L. M., \& Woessman, L. (2020). Long-run trends in the US SES-achievement gap. Program on Education Policy and Governance Working Papers Series. PEPG 20-01. Program on Education Policy and Governance. https://doi.org/10.3386/w26764

Hodges, C., Moore, S., Lockee, B., Trust, T., \& Bond, A. (2020). The difference between emergency remote teaching and online learning. Educause Review, 27, 1-12.

Kavrayıc1, C., \& Kesim, E. (2021). COVID-19 pandemisi sürecinde okul yönetimi: nitel bir araştırma. Kuram ve Uygulamada Egitim Yönetimi Dergisi, 27(1), 1005-1060. https://doi.org/10.14527/kuey.2014.014

Malik, S., \& Rana, A. (2020). E-Learning: role, advantages, and disadvantages of its implementation in higher education. JIMS8I-International Journal of Information Communication and Computing Technology, 8(1), 403-408. https://doi.org/10.5958/2347-7202.2020.00003.1

Malkus, N. (2020). Too little, too late: A hard look at spring 2020 remote learning. American Enterprise Institute. http://www.jstor.org/stable/resrep25360

Prime, H., Wade, M., \& Browne, D. T. (2020). Risk and resilience in family well-being during the COVID-19 pandemic. American Psychologist, 75(5), 631-643. https://doi.org/10.1037/amp0000660

Quezada, R. L., Talbot, C., \& Quezada-Parker, K. B. (2020). From bricks and mortar to remote teaching: A teacher education program's response to COVID-19. Journal of Education for Teaching, 46(4), 472-483. https://doi.org/10.1080/02607476.2020.1801330

Ribeiro, R. (2020, April)."How university faculty embraced the remote learning shift." EdTech Magazine. Retrieved from https://edtechmagazine.com/higher/article/2020/04/howuniversity-faculty-embraced-remote-learning-shift

Sá, M. J., \& Serpa, S. (2020). COVID-19 and the promotion of digital competencies in education. Universal Journal of Educational Research, 8(10), 4520-4528. https://doi.org/10.13189/ujer.2020.081020

Sheffer, J. A., \& Hunker, S. D. (2019). Digital curation: pedagogy in the archives. Pedagogy: Critical Approaches to Teaching Literature, Language, Composition, and Culture, 19(1), 79-105. https://doi.org/10.1215/15314200-7173771

Slavin, R. E., \& Storey, N. (2020). The U.S. educational response to the COVID-19 pandemic. Best Evidence Chinese Education, 5(2), 617-633. https://doi:10.15354/bece.20.or027 
Strielkowski, W. (2020). COVID-19 pandemic and the digital revolution in academia and higher education. https://doi:10.20944/preprints202004.0290.v1

The Jed Foundation. (2021, April 22). The fluent family study survey. Retrieved from http://www.jedfoundation.org/

Trinidad, J. E. (2021). Equity, engagement, and health: school organizational issues and priorities during COVID-19. Journal of Educational Administration and History, 53(1), 67-80. https://doi.org/10.1080/00220620.2020.1858764

Vlachopoulos, D. (2020). COVID-19: Threat or opportunity for online education? Higher Learning Research Communications, 10 (1), 2. https://doi.org/10.18870/hlrc.v10i1.1179

Walling, D. R. (2016). 2016 AECT International Convention Summary. Tech Trends, 61(1), 5-7. https://doi:10.1007/s11528-016-0148-y

Wilmer, H. H., Sherman, L. E., \& Chein, J. M. (2017). Smartphones and cognition: a review of research exploring the links between mobile technology habits and cognitive functioning. Frontiers in Psychology, 8, 605. https://doi.org/10.3389/fpsyg.2017.00605

Yang, X. (2020). Teachers' perceptions of large-scale online teaching as an epidemic prevention and control strategy in China. ECNU Review of Education, 3(4), 739-744. https://doi.org/10.1177/2096531120922244 